\title{
Forecasting the quality of mineral oils during oil refining according to the fuel and oil flow chart at Atyrau Refinery
}

\author{
Aigul Bukanova ${ }^{1, *}$, Fazilat Kayrliyeva $^{1}$, Saule Bukanova ${ }^{1}$, Nagima Karabassova ${ }^{1}$, and Lydia Sakipova ${ }^{1}$ \\ ${ }^{1}$ Industrial and Process Faculty, Atyrau University of Oil and Gas, Atyrau, Kazakhstan
}

\begin{abstract}
The article discusses the problem of rational oil refining at Atyrau Refinery. Based on a detailed study of the properties of low-sulfur oils of Kazakhstan, in order to assess the potential for the selection of petroleum oils, effective refining methods with modern technologies are shown. A graph is given that allows us to assess the raw mate-rial potential of the Republic of Kazakhstan for lube fractions of oil. The potential reserve of the considered deposits can fully meet the needs of the Republic in oils. The physical and chemical properties of crude oil sup-plied to Atyrau refinery, with a view to their use as raw materi-als for the oil refining and production. The results of experiments on hydrocracking of the plant's vacuum gasoil are also presented, indicating that this refining option allows you to obtain not only light distillates (gasoline and diesel fuel), but also excellent base oils. This can significantly advance the oil refining in the enterprise as a whole. On the basis of experimental studies, the correlation dependence of the viscosity index on the hydrocarbon-type composition of oils was revealed, which allows predicting the quality of the resulting product.
\end{abstract}

\section{Introduction}

The results of scientific research and practice of recent decades show that the most promising step towards expanding the raw material base for oil refineries is to use such minerals as high pour point oils and their rational refining.

The energy and environmental problems of processing heavy oils and oil residues [1], the complexity of their composition, necessitate the search for new process methods for their processing [2], as well as the modernization of existing layouts in order to obtain the maximum possible amount of light fractions and improve their quality [3]. The issue of involving unused, cheaper and more affordable types of raw materials, including waste from the oil and oil processing industry, remains relevant.

The choice of an effective processing method is directly related to the physical and chemical properties of the processed raw materials, which are characterized by a very complex chemical composition [2].

Heavy oils are characterized by a high density (920$\left.1000 \mathrm{~kg} / \mathrm{m}^{3}\right)$ and viscosity (50-10000 $\left.\mathrm{MPa} \cdot \mathrm{s}\right)$, a low content of fuel fractions, as well as an increased content of sulfur and metals [4].

Also, a priority for the development of the economy of Kazakhstan is the development and implementation of technologies adapted to the raw material conditions of Kazakhstan and allowing the processing of heavy, viscous and high-sulfur oils to produce not only motor fuels, but also mineral oils. As you know, all oil refineries in Kazakhstan operate on the fuel option, that is, other valuable qualities of oil are underutilized, which contains a significant amount of oil and paraffin components, while the entire volume of lubricants consumed is imported, and with enormous costs for purchase and transportation.

The paper purpose is to study the characteristics of Kazakhstan's oils for their use as raw materials for refining and obtaining mineral oils in the Republic; to provide theoretical and practical justification for the use of the hydrocracking process when producing high-index oils at Atyrau Refinery and to evaluate their quality characteristics.

Relevance. For the development of the economy of Kazakhstan, the priority is the development and implementation of technologies adapted to the raw material conditions of Kazakhstan and allowing the refining of heavy and viscous oils in order to make them competitive on the world market.

\section{Objects and Methods of Research}

At the same time, Kazakhstan has the most unique raw materials for the production of oils and paraffin, which include Mangyshlak (Uzen, Zhetybay) [5], Kumkol, and the oil of the Emba region.

The diagram (Fig. 1) shows 27 oil fields in Kazakhstan, which are characterized as raw materials for the production of lubricants. A common feature of these high-quality lube fractions of oil is the high oil yield of lube fractions with high viscosity indices.

The high-viscosity and high-potential lube frac-tions of oil them among are the oil fields: Krykmyltyk -

* Corresponding author: A.Bukanova@aogu.edu.kz 


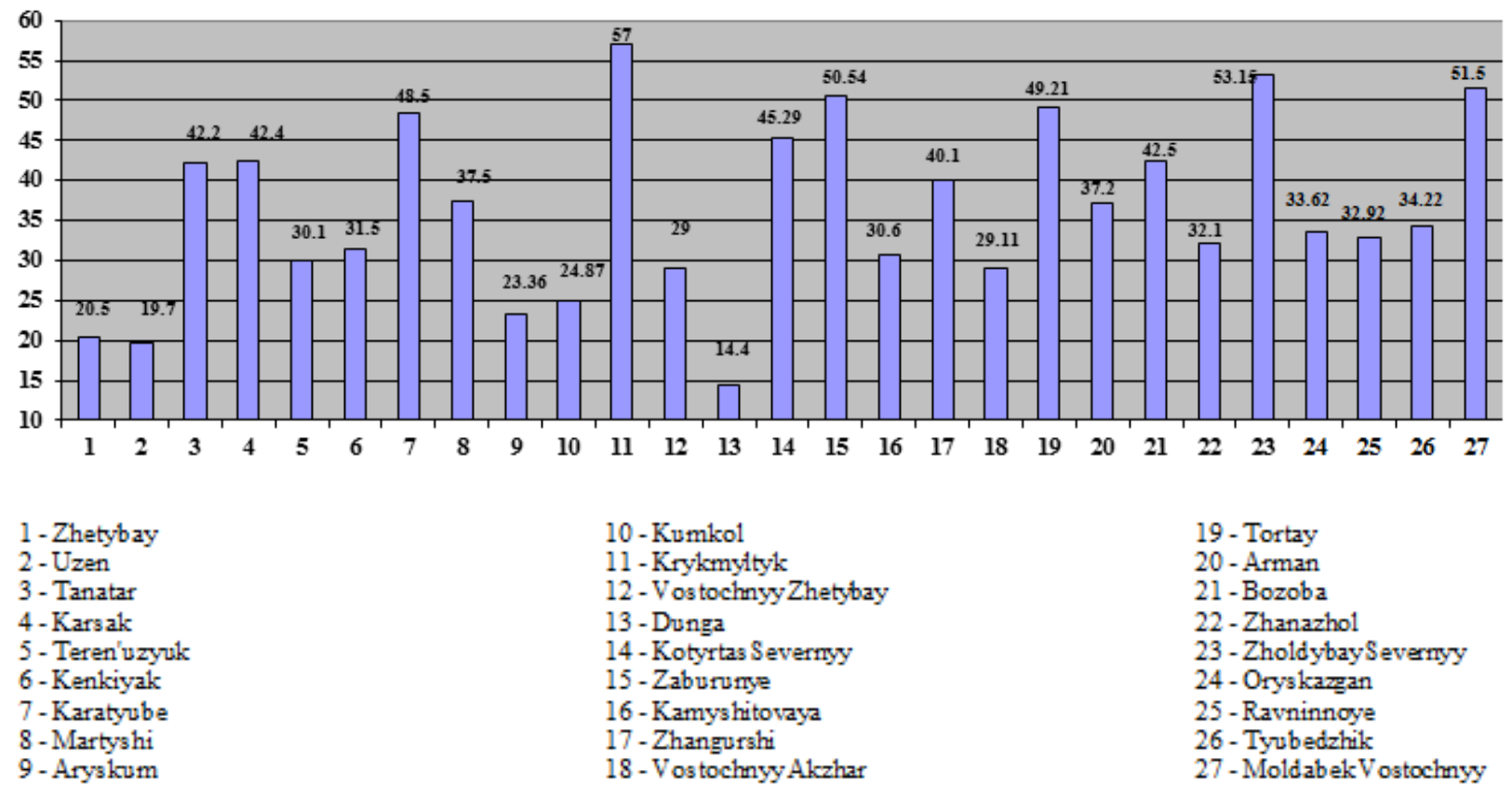

Fig. 1. The content of lube fractions in the oils of Kazakhstan.

production of lube fractions of $57 \%$ of oil (VI 125), Zholdybai North - production of lube fractions of $53.15 \%$ of oil (VI 116), Moldabek East - production of lube fractions of $51.5 \%$ of oil (IV 110), Zaburunye production of lube fractions of $50.5 \%$ oil (VI 119), Torty - production of lube fractions of $49.2 \%$ of oil (VI 102), Karatyube - production of lube fractions of $48.5 \%$ of oil (VI 91), Kotyrtas North - production of lube fractions of $45.29 \%$ of oil (VI 103) [6], Bozoba - production of lube fractions of $42.5 \%$ of oil (VI 119), Tanatar - production of lube fractions of $42.2 \%$ of oil (VI 96), Zhangurshi production of lube fractions of $40.1 \%$ of oil (VI 121) [7, 8].

\section{Results and Discussion}

The analysis of the location of the deposits, as well as the study and research of their physical and chemical properties, showed that most of the oil oils are concentrated in Western Kazakhstan, in Atyrau region. The Atyrau Refinery is the only oil refinery in the republic that processes Kazakhstan oil from the Western region of the republic and this is economically advantageous due to the small distances between the refinery and the oil fields. The potential reserve of the-se deposits can fully meet the needs of the republic in oils [9].

To enhance oil refinery, it is necessary to widely develop secondary destructive processes (catalytic cracking, hydrocracking, thermal processes), based on the separate processing of vacuum distillates and oil residues, while ensuring that gasoline and diesel fuel meet new environmental requirements. Deep conver-sion of vacuum distillates into motor fuel is achieved by using the processes of catalytic cracking and hydrocracking [10].

In 2017, as a result of the third reconstruction stage, the Atyrau Refinery commissioned a deep oil refining complex (hereinafter referred to as DORC), designed for refinery of residual heavy oil products into high-quality motor fuels [11]. The initial raw materials for DORC will be vacuum distillate from the atmospheric-vacuum unit plant, heavy coking gas oil from the delayed coker, and straight-run fuel oil, as well as heavy aromatics and heavy refined petroleum from the aromatic hydrocarbon production complex under construction.

The main commercial products are: the compo-nent of gasoline corresponding to the level of the Euro-4-5 standard, diesel fuel, propylene, compressed gases (Table 1), but the fuel option of oil refining remains. At the same time, the refinery process flow does not use such a promising process as hydrocracking to obtain a wide range of fuels and lubricants that meet all the requirements of modern standards [12].

For the fuel-oil refinery option, we investigated the possibility of refining vacuum gas oil, fuel oil and tar from the Atyrau refinery at the catalytic cracking and hydrocracking plants. 
Table 1. Material balance of catalytic cracking.

\begin{tabular}{|c|l|c|c|}
\hline$\#$ & \multicolumn{1}{|c|}{ Name } & \multicolumn{2}{|c|}{ Production of thousands of tons/year } \\
\cline { 3 - 4 } & & $\begin{array}{c}\text { Before } \\
\text { reconstruction }\end{array}$ & $\begin{array}{c}\text { After the } \\
\text { reconstruction }\end{array}$ \\
\hline 1 & Ai-80 Gasoline & 397.3 & 0.0 \\
\hline 2 & AI-92 Gasoline & 149.1 & 840.0 \\
\hline 3 & AI-95 Petrol & 6.3 & 894.0 \\
\hline 4 & Benzene & 0.0 & 133.0 \\
\hline 5 & Paraxylene & 0.0 & 496.0 \\
\hline 6 & Jet fuel/kerosene & 51.3 & 365.0 \\
\hline 7 & Diesel fuel & 1190.5 & 1460.0 \\
\hline 8 & Fuel oil M-100 & 1697.8 & 150.0 \\
\hline
\end{tabular}

For the purposes of the study, the selected oils were delivered to the Atyrau refinery. The characteristics of these oils are given in Table 2.

The oils are characterized by a low sulfur con-tent, have a low coking capacity, but differ in their fractional composition and paraffin content.

Table 2. Characteristics of oils.

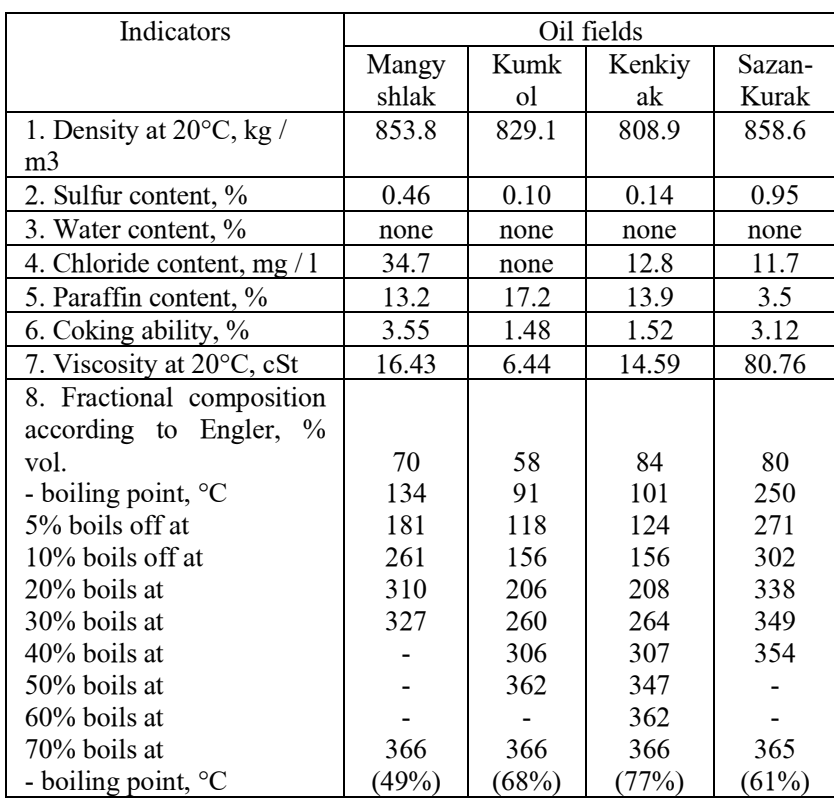

Oil was fractionated [13] by selecting gasoline (s.b. $\left.180^{\circ} \mathrm{C}\right)$, diesel $\left(180-350^{\circ} \mathrm{C}\right)$ fractions and vacuum gasoil $\left(350-500^{\circ} \mathrm{C}\right)$. The results of experiments on oil rectification on crude oil atmospheric distillation device are presented in Table 3. From this table, it can be seen that the highest yield of the gasoline fraction from the oil of Kenkiyak field is $33.7 \%$, and the vacuum gas oil from the oil of Sazan-Kurak field is $32.2 \%$.
Table 3. Distillate yields from Kazakhstan oils.

\begin{tabular}{|l|c|c|c|c|}
\hline \multicolumn{2}{|c|}{ Indicators } & \multicolumn{4}{c|}{ Oil fields } \\
\cline { 2 - 5 } & $\begin{array}{c}\text { Mangysh } \\
\text { lak }\end{array}$ & $\begin{array}{c}\text { Kumko } \\
1\end{array}$ & $\begin{array}{c}\text { Kenkiy } \\
\text { ak }\end{array}$ & $\begin{array}{c}\text { Sazan- } \\
\text { Kurak }\end{array}$ \\
\hline $\begin{array}{l}\text { Yield, \% } \\
\left.\text { - gasoline (s.b.-180 }{ }^{\circ} \mathrm{C}\right)\end{array}$ & 16.2 & 31.2 & 33.7 & 6.2 \\
- diesel fraction (180- & & & & \\
350 ${ }^{\circ} \mathrm{C}$ ) & 22.3 & 27.0 & 21.3 & 24.1 \\
- vacuum gas oil (350- & & & & \\
500 $\left.{ }^{\circ} \mathrm{C}\right)$ & 27.6 & 25.9 & 27.0 & 32.2 \\
- tar & 32.4 & 14.7 & 16.8 & 36.5 \\
- losses & 1.5 & 1.2 & 1.2 & 1.0 \\
\hline
\end{tabular}

The main characteristics of petroleum distillates and tar obtained by atmospheric-vacuum distillation of oils are shown in Tables 4-7.

The results obtained showed that the gasoline fractions obtained from all the studied oils, except for the oil of Sazan-Kurak field (Table 4), have lower density values $\left(743-760 \mathrm{~kg} / \mathrm{m}^{3}\right)$, contain very little sulfur, and the lowest sulfur content in Mangyshlak oil (0.012\%). The gasoline of the Sazan-Kurak oil was heavier (density-794.9 $\mathrm{kg} / \mathrm{m}^{3}$ ) and more sulfurous (sulfur $0.20 \%)$.

Diesel fractions (Table 5) of paraffin oils (Mangyshlak, Kumkol, Kenkiyak) have a low viscosity, but increased values of the turbidity and solidification temperature. Sazan-Kurak oil produces diesel fractions with good low-temperature properties, but has higher viscosity values.

Table 4. Characteristics of gasoline.

\begin{tabular}{|c|c|c|c|c|}
\hline \multirow{2}{*}{ Indicators } & \multicolumn{4}{|c|}{ Oil fields } \\
\cline { 2 - 5 } & $\begin{array}{c}\text { Mangysh } \\
\text { lak }\end{array}$ & Kumkol & Kenkiyak & $\begin{array}{c}\text { Sazan- } \\
\text { Kurak }\end{array}$ \\
\hline $\begin{array}{l}\text { 1. Density at } 20^{\circ} \mathrm{C}, \\
\mathrm{kg} / \mathrm{m}^{3}\end{array}$ & 755.6 & 743.0 & 747.2 & 794.9 \\
\hline 2. Sulfur content, $\%$ & 0.012 & 0.048 & 0.035 & 0.20 \\
\hline
\end{tabular}

Table 5. Characteristics of diesel fractions.

\begin{tabular}{|l|c|c|c|c|}
\hline \multirow{2}{*}{ Indicators } & \multicolumn{4}{|c|}{ Oil fields } \\
\cline { 2 - 5 } & $\begin{array}{c}\text { Mangysh } \\
\text { lak }\end{array}$ & Kumkol & Kenkiyak & $\begin{array}{c}\text { Sazan- } \\
\text { Kurak }\end{array}$ \\
\hline \multicolumn{1}{|c|}{1} & 2 & 3 & 4 & 6 \\
\hline $\begin{array}{l}\text { 1. Density at } \\
\text { 20 } \mathrm{C}, \mathrm{kg} / \mathrm{m}^{3}\end{array}$ & 830.3 & 830.1 & 828.1 & 879.8 \\
\hline $\begin{array}{l}\text { 2. Sulfur content, } \\
\%\end{array}$ & 0.20 & 0.091 & 0.096 & 0.30 \\
\hline $\begin{array}{l}3 . \quad \text { Temperature, } \\
{ }^{\circ} \mathrm{C}\end{array}$ & & & & \\
- opacity & +8 & +8 & +8 & -30 \\
- pour point \\
- flash point & -12 & -13 & -10 & -47 \\
\hline $\begin{array}{l}4 . \quad \text { Viscosity at } \\
\text { 20 } 0^{\circ} \mathrm{C}, \mathrm{cSt}\end{array}$ & 62 & 64 & 63 & 59 \\
\hline
\end{tabular}

Analyses of vacuum gas oils (Table 6) have shown that they all contain a lot of paraffin \& naphthenic and light aromatic hydrocarbons, which, as a rule, have good viscosity\& temperature properties. Vacuum gas oils of Kumkol and Kenkiyak oils are particularly distinguished, in which the sum of paraffin \& naphthenic and light aromatic hydrocarbons reaches $89-90 \%$.

Tar residues (Table 7) are characterized by relatively low values of density and coking ability, which is 
associated with an insignificant content of asphaltresinous substances from 13 to $25 \%$.

We performed experiments on hydrocracking of vacuum gas oil obtained from Mangyshlak oil [14].

The experiments were carried out at space velocities of $0.5 \mathrm{~h}^{-1}$ and $1.0 \mathrm{~h}^{-1}$. The results of hydrocracking are presented in Table 8 .

With an increase in the space velocity, feed rate of the raw material, the yield of hydrogenate increases (Table 8).

Table 6. Characteristics of vacuum gas oils.

\begin{tabular}{|c|c|c|c|c|}
\hline \multirow{2}{*}{ Indicators } & \multicolumn{4}{|c|}{ Oil fields } \\
\hline & $\begin{array}{c}\text { Mangysh } \\
\text { lak }\end{array}$ & Kumkol & Kenkiyak & $\begin{array}{l}\text { Sazan- } \\
\text { Kurak }\end{array}$ \\
\hline $\begin{array}{l}\text { 1. Density at } 20^{\circ} \mathrm{C} \text {, } \\
\mathrm{kg} / \mathrm{m}^{3}\end{array}$ & 892.2 & 885.7 & 882.1 & 880.2 \\
\hline 2. Sulfur content, $\%$ & 1.16 & 0.12 & 0.42 & 0.95 \\
\hline $\begin{array}{l}\text { 3. Viscosity at } \\
100^{\circ} \mathrm{C}, \mathrm{cSt} \\
\text { at } 70^{\circ} \mathrm{C}, \mathrm{cSt}\end{array}$ & $\begin{array}{c}6.15 \\
12.30\end{array}$ & $\begin{array}{c}5.80 \\
11.40\end{array}$ & $\begin{array}{l}5.40 \\
8.70\end{array}$ & $\begin{array}{c}8.20 \\
20.20\end{array}$ \\
\hline 4. Pour point, ${ }^{\circ} \mathrm{C}$ & 40 & 35 & 36 & 10 \\
\hline $\begin{array}{l}\text { 5. Hydrocarbon } \\
\text { type content, \% } \\
-\quad \text { paraffin \& \& } \\
\text { naphthenic }\end{array}$ & & & & \\
\hline - light aromatic & 63.9 & 77.0 & 79.9 & 65.9 \\
\hline - medium aromatic & 19.8 & 13.2 & 9.4 & 15.3 \\
\hline - heavy aromatic & 2.3 & 1.7 & 3.2 & 5.9 \\
\hline & 8.4 & 7.3 & 4.9 & 9.3 \\
\hline- resin I & 2.2 & 0.2 & 1.0 & 1.6 \\
\hline - resin II & 3.4 & 0.6 & 1.6 & 2.0 \\
\hline $\begin{array}{l}\text { the sum of paraffin } \\
\& \text { naphthenic and } \\
\text { light aromatic } \\
\text { hydrocarbons }\end{array}$ & & & & \\
\hline & 83.7 & 90.2 & 89.3 & 81.2 \\
\hline
\end{tabular}

Table 7. Characteristics of tars.

\begin{tabular}{|l|c|c|c|c|}
\hline \multirow{2}{*}{ Indicators } & \multicolumn{4}{|c|}{ Oil fields } \\
\cline { 2 - 5 } & $\begin{array}{c}\text { Mangysh } \\
\text { lak }\end{array}$ & $\begin{array}{c}\text { Kum } \\
\text { kol }\end{array}$ & Kenkiyak & $\begin{array}{c}\text { Sazan- } \\
\text { Kurak }\end{array}$ \\
\hline 1. Density at 20 ${ }^{\circ} \mathrm{C}, \mathrm{kg}$ & & & & \\
/ $\mathrm{m}^{3}$ & 963.3 & 951.1 & 955.4 & 959.3 \\
\hline 2. Sulfur content, \% & 2.25 & 0.17 & 1.24 & 1.51 \\
\hline 3. Coking ability, \% & 11.4 & 10.0 & 11.1 & 8.3 \\
\hline 5. Hydrocarbon type & & & & \\
content, \% & & & & \\
- paraffin-naphthenic & 33.7 & 38.4 & 33.9 & 40.6 \\
- light aromatic & 13.8 & 14.6 & 19.7 & 14.4 \\
- medium aromatic & 2.0 & 3.5 & 4.2 & 2.6 \\
- heavy aromatic oils & 26.5 & 23.7 & 17.7 & 23.7 \\
- resin I & 6.7 & 7.2 & 9.3 & 4.8 \\
- resin II & 13.5 & 10.5 & 13.0 & 11.1 \\
- asphaltenes & 3.8 & 2.1 & 2.5 & 2.8 \\
\hline \multicolumn{4}{|r}{}
\end{tabular}

Table 8. Yields of hydrocracking products.

\begin{tabular}{|l|c|c|}
\hline \multirow{2}{*}{ Indicators } & \multicolumn{2}{|c|}{ Space velocity } \\
\cline { 2 - 3 } & 0.5 hour $^{-1}$ & 1.0 hour $^{-1}$ \\
\hline 1. Temperature, ${ }^{\circ} \mathrm{C}$ & 393 & \\
- in the upper part of the reactor & 403 & 385 \\
- in the middle of the reactor & 407 & 396 \\
- in the lower part of the reactor & 9.9 & 103 \\
\hline 2. Pressure, MPa & 40 & 80 \\
\hline 3. Raw material loading, $\mathrm{ml} /$ hour & & \\
\hline 4. Processed: & 200 & 240 \\
- vacuum gas oil, ml & 80 & 96 \\
-hydrogen, nm ${ }^{3 *}$ ) & 167.1 & 204.4 \\
\hline 5. Hydrogenate obtained, g & \multicolumn{2}{|}{} \\
\hline
\end{tabular}

Switching to a more rigid mode (increasing the temperature, reducing the feed of raw materials) leads to a decrease in the yield of hydrogenate.

The material balance of experiments on hydrocracking of vacuum gas oil is presented in Table 9.

All light products are low in sulfur. Gasoline, due to its high content of napthenes, is a good raw material for reforming. Jet fuel is characterized by a low content of aromatic hydrocarbons and a low pour point.

It is also possible to obtain fractions of diesel fuel with a low pour point. Light lube fractions are suitable for the production of white medical oils and oil-soluble sulfonates.

Table 9. Material balance of experiments.

\begin{tabular}{|l|c|c|}
\hline \multirow{2}{*}{ Indicators } & \multicolumn{2}{|c|}{ Space velocity } \\
\cline { 2 - 3 } & $\begin{array}{c}0.5 \text { hour }^{-1} \\
\text { (experiment 1) }\end{array}$ & $\begin{array}{c}1.0 \text { hour }^{-1} \\
\text { (experiment } 2)^{-1}\end{array}$ \\
\hline $\begin{array}{l}\text { 1. Gas yield, including losses, } \\
\%\end{array}$ & 6.0 & 4.5 \\
\hline 2. Yield of liquid products, \% & & \\
- gasoline (s.b/ $\left.-180^{\circ} \mathrm{C}\right)$ & 15.9 & 12.7 \\
- diesel fuel $\left(180-350^{\circ} \mathrm{C}\right)$ & 55.4 & 50.9 \\
- oil distillate $\left(350^{\circ} \mathrm{C}-\right.$ f.b) & 24.9 & 34.1 \\
\hline Total & 102.2 & 102.2 \\
\hline
\end{tabular}

From the material balance of experiments on hydrocracking of vacuum gas oil, it can be seen that the shorting of the hydrocracking regime $\left(0.5 \mathrm{~h}^{-1}\right)$ increases the yield of gas and fuel fractions in comparison with oil, and vice versa.

The results of distillate analyses are presented in Table 10. If the fuel fractions of hydrocracking are characterized, an increase in the feed space velocity of raw materials ( 1 hour $\left.^{-1}\right)$ leads to a slight deterioration in the quality indicators of these distillates. 
Table 10. Characteristics of distillate hydrocracking products.

\begin{tabular}{|l|c|c|c|c|}
\hline \multirow{2}{*}{ Indicators } & \multicolumn{2}{|c|}{ Experiment 1 } & \multicolumn{2}{c|}{ Experiment 2 } \\
\cline { 2 - 5 } & $\begin{array}{c}\text { Gasolin } \\
\mathrm{e}\end{array}$ & $\begin{array}{c}\text { Diesel } \\
\text { fuel }\end{array}$ & Gasoline & $\begin{array}{c}\text { Diesel } \\
\text { fuel }\end{array}$ \\
\hline $\begin{array}{l}1 . \text { Density at } 20^{\circ} \mathrm{C}, \\
\mathrm{kg} / \mathrm{m}^{3}\end{array}$ & 727.6 & 830.6 & 732.5 & 832.1 \\
\hline 2. Sulfur content, \% & 0.001 & 0.005 & 0.002 & 0.008 \\
\hline $\begin{array}{l}3 . \quad \text { Viscosity at } \\
20^{\circ} \mathrm{C}, \mathrm{cSt}\end{array}$ & - & 3.28 & - & 3.40 \\
\hline $\begin{array}{l}\text { 4. Temperature, }{ }^{\circ} \mathrm{C} \\
\text { - opacity } \\
\text { - pour point } \\
\text { - flash point }\end{array}$ & - & -8 & - & -6 \\
\hline
\end{tabular}

Hydrocracking diesel fuel fully meets the requirements for environmentally friendly brands of summer diesel fuel.

Gasoline with an octane rating of about 70 will also be easily disposed of at the refinery as a component of commercial gasoline.

In general, the results of experiments on hydrocracking of Atyrau refinery vacuum gas oil indicate that such refining of residual hydrocarbon raw materials, along with the production of light distillates (gasoline and diesel fuel) at the level of $63.6-71.3 \%$ for the initial raw materials of hydrocracking, also allows you to get excellent base oils. This can significantly deepen the refining of oil in the enterprise as a whole.

In general, the results of experiments on hydrocracking of Atyrau refinery vacuum gas oil indicate that such refining of residual hydrocarbon raw materials, along with the production of light distillates (gasoline and diesel fuel) at the level of $63.6-71.3 \%$ for the initial raw materials of hydrocracking, also allows you to get excellent base oils.

This can significantly deepen the refining of oil in the enterprise as a whole.

The results of analysis of seven samples of dewaxed oils obtained from vacuum gas oils and hydrocracking residues of the Kazakhstan vacuum gas oil are also presented.

Experiments on dewaxing were carried out at a filtration temperature of minus $27^{\circ} \mathrm{C}$, the solvent-raw material ratio was $4: 1$ at the crystallization stage and 1.5:1 at the washing stage.

Dewaxing of vacuum gas oils $\left(350-500^{\circ} \mathrm{C}\right)$ of Kumkol and Kenkiyak oils produce dewaxed oils with an average viscosity index of 83-86.

When dewaxing the Mangyshlak oil vacuum gas oil, a dewaxed oil with a viscosity index of 76 is obtained. This is due to the higher content of heavy aromatic and resinous components in the oil from Mangyshlak vacuum gas oil, which reaches $15.8 \%$ (in total).

With an increase in the content of polycyclic compounds in the purified oil, the value of the viscosity index decreases quite sharply.

The products of dewaxing of narrower fractions of vacuum gas oils obtained from Kumkol and Kenkiyak oils have higher values of the viscosity index. When comparing the quality indicators of dewaxed oils obtained from vacuum gas oils with boiling limits of $370-450{ }^{\circ} \mathrm{C}$ with the analogous data for vacuum gas oils of $350-500^{\circ} \mathrm{C}$, it can be noted that the quality of oils from a close-cut fraction of raw materials is noticeably better than for a wider fraction (the values of the viscosity indices increased by 10-11 points).

Hydrocracking products [15] are characterized by very low densities, sulfur content and very high concentrations of paraffin \& naphthenic and light aromatic hydrocarbons, the share of high-viscosity paraffin \& naphthenic and light aromatic hydrocarbons reaches the level of $90-95 \%$ with a low content of a mixture of heavy aromatic hydrocarbons and resins (3.2 $-6.0 \%$ ) (Table 11).

Table 11. Comparative hydrocarbon type contents of the obtained dewaxed oils.

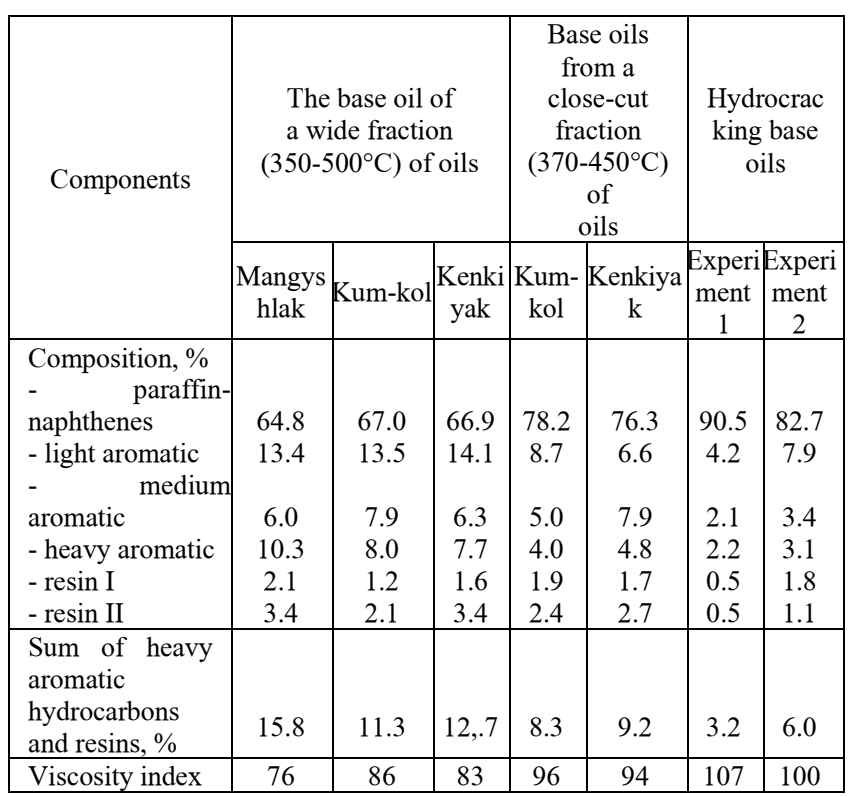

The curve of the change in the value of the vis-cosity index from the content of the sum of aromatic hydrocarbons and resins is described by a well-defined correlation equation of the form:

$$
\text { Viscosity Index }=\mathrm{A} \cdot \mathrm{S}_{\mathrm{HAH}+\mathrm{c}}+\mathrm{B} \text {, }
$$

where $\mathrm{A}$ and $\mathrm{B}$ are correlation coefficients,

$\mathrm{S}_{\mathrm{HAH}}+\mathrm{C}$ is the sum of the concentrations of heavy aromatic hydrocarbons and resins in \% wt. (Figure 2).

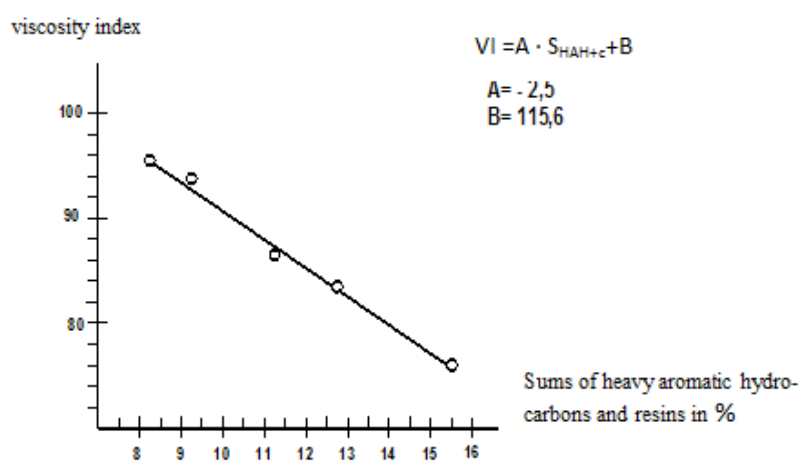

Fig. 2. Dependence of the viscosity index of base oils on the content of heavy aromatic hydrocarbons and resins (in total).

From the presented data, it is obvious that the share of high-index paraffin-naphthenic and light aromatic 
hydrocarbons after dewaxing is kept at the level of 90$95 \%$ with a low content of a mixture of heavy aromatic hydrocarbons and resins $(3.2-6.0 \%)$.

A comparison of the results shown in Table 11 shows that the values of the viscosity index of dewaxed oils are well correlated with the results of determining the hydrocarbon type content of these oils. The higher the paraffin \& naphthenic and light aromatic hydrocarbons in dewaxed oils, the higher the viscosity index. Hydrocracking base oils have the highest content of paraffin \& naphthenic and light aromatic hydrocarbons, and a correspondingly high viscosity index.

\section{Conclusion}

Thus, knowing the hydrocarbon type content of dewaxed oil distillates, using this equation, it is possible to predict their viscosity characteristics with sufficient accuracy in the form of the value of the viscosity index. The average error of such a determination is 0.9 units of the viscosity index $[16,17]$.

In general, the results of experiments on hydrocracking of Atyrau refinery vacuum gas oil indicate that such refining of residual hydrocarbon raw materials, along with the production of light distillates (gasoline and diesel fuel) at the level of $63.6-71.3 \%$ for the initial raw materials of hydrocracking, also allows you to get excellent base oils. This may significantly en-hance the oil refining in the enterprise as a whole.

Thus a necessary condition for achieving a posi-tive result seems to be the right set of technologies (plants), ensure the production of high quality motor fuels, oils, the corresponding requirements of the world standards, and raw materials for petrochemicals, which ultimately will enhance the process of oil refining, which is today an important task for Kazakhstan refin-eries.

\section{References}

1. O. Karimov, G. Shakulikova, N. Ishmukhamedova, E. Karimov, Web of Conferences, 175, 11030 (2020) DOI: 10.1051/e3sconf/202017511030

2. E.K. Ongarbayev, E.O. Doszhanov, Z.A. Mansurov, Refining of heavy oils, oil residues and waste (Almaty: Kazakh University, 254, 2011)

3. R.R. Khismiev, S.M. Petrov, N.Yu. Bashkirtseva, The current state and potential of refining heavy high-viscosity oils and natural bitumen, Bulletin of KNRTU, 312-315 (2014)

4. E.A. Galiullin, R.Z. Fakhrutdinov, New technologies for refining heavy oils and natural bitumen, Bulletin of Technological university, 19 (4), 47-51 (2016)

5. A.Sh. Akzhigitov, T.M. Bisenova, Oil of new deposits of the Triassic horisonts of the Mangyshlak peninsula, Oil and gas, 3, 92-98 (2000)

6. Commercial oils and oil mixtures transported through the main oil pipelines of the Republic of
Kazakhstan, Guide. Ch. 1. Almatykitap, 404 (2005)

7. A.S. Bukanova, T.P. Serikov, G.A. Orazova, Prospects for obtaining oils in the refining of oils of Western Kazakhstan, Bulletin of AING, 1-2, 92-95 (2001-2002)

8. I.R. Khairudinov, A.S. Bukanova, T.P. Serikov, G.A. Orazova, Potential possibilities of obtaining base oils from the oils of Kazakhstan, Proceedings of the $\mathrm{V}$ Kazakh-Russian international scientific and practical conference "Mathematical modeling of scientific, technological and environmental problems in the oil and gas industry", Atyrau, 158-162 (2005)

9. A.S. Bukanova, Oil of Kazakhstan for the production of oils, Bulletin of the Astrakhan State Technical University, Scientific Journal, 2 (43), 236-239 (March-April 2008)

10. N.K. Nadirov, G.A. Orazova, A.S. Bukanova, Prospects for deep oil refining at the Atyrau refinery according to the fuel and oil scheme [Electronic resource], Oil and gas, 1 (55), 61-67 (2010) Available at:

11.https://www.anpz.kz/press_center/news/?ELEMENT _ID $=43140$

12. A.I. Abdullin, I.R. Siraev, Hydrocracking as a process of obtaining diesel fuel, Bulletin of Technical University, 19 (10), 41-43 (2016)

13. I.R. Khairudinov, A.S. Bukanova, T.P. Serikov, G.A. Orazova, Assessment of the possibility of oil refining at Atyrau refinery according to the oil layout, Documents of the international scientific and practical conference "Oil and Gas Processing and Petrochemistry - 2005", Ufa, 24 (2005)

14. I.R. Khairudinov, A.S. Bukanova, T.I. Sazhina, T.P. Serikov, G.A. Orazova, Obtaining highviscosity base oils by hydrocracking, Oil and gas, 6, 31-34 (2005)

15. A.I. Abdullin, I.R. Siraev, Hydrocracking as a process of obtaining diesel fuel, Bulletin of Technical University, 19 (10), 41-43 (2016)

16. A.S. Bukanova, Correlation equation of the dependence of the oil viscosity index on the content of aromatic hydrocarbons and resins, Bulletin of the National Academy of Sciences of the Republic of Kazakhstan, 4, 136-139 (2005)

17. Method for regulating the quality of base oils, Patent for the invention $\mathbf{1 8 7 7 9}$ 